Supplement of Atmos. Chem. Phys., 19, 5293-5311, 2019

https://doi.org/10.5194/acp-19-5293-2019-supplement

(c) Author(s) 2019. This work is distributed under

the Creative Commons Attribution 4.0 License.

(c) (1)
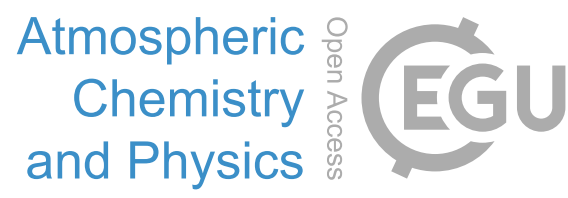

Supplement of

\title{
Annual variability of ice-nucleating particle concentrations at different Arctic locations
}

\section{Heike Wex et al.}

Correspondence to: Heike Wex (wex@ tropos.de)

The copyright of individual parts of the supplement might differ from the CC BY 4.0 License. 


\section{Background measurements}

Following a recommendation given in Polen et al. (2018), Figs. S1 to S3 show frozen fractions $\left(f_{\text {ice }}\right)$, i.e., the measured parameter, for field blanks together with some spectra of $f_{\text {ice }}$ for pure water and for filter samples that were sampled in the days directly before and after the field blank was taken. Field blanks were treated similar to filters onto which sampling was done, only were they not subjected to sampling air through them. They did, however, spend time in the sampler. The three different panels in Fig. S1 clearly show, that the background level is influenced by the atmospheric INP concentrations, as field blanks taken from April until October show a much larger signal than those collected during the other months. Therefore, and as the availability of field blanks varied between the different measurement stations (there were none for VRS, two for Ny Ålesund and Utqiagivik each, and 9 from Alert), signals from the field blanks were not subtracted from the signals from the samples.

To show the influence of the background on the measurements in more detail, for five filter samples from Alert the background was subtracted. These five samples were selected such that the background had the highest possible impact. From the upper panel of Figs. S1, both samples were included (April 29 and May 07), relating to the same field blank which had been taken on May 07. From the middle panel, the higher one of the two field blanks was taken, together with the lower one of the two samples that it was collected closest to (October 21). Similarly, from the lowest panel, the highest field blank with the lowest of the two related samples (June 10) and the lowest sample (January 27) with the related field blank were included. The five spectra of $f_{i c e}$ for the filter samples are shown together with those for the field blanks in the two left panels of Fig. S4. Subtraction of the background was done by converting $f_{i c e}$ to concentrations of INP per volume of water/suspension (known as $K(T)$ in the nomenclature by Vali, 2019), following Polen et al. (2018). K(T) from the field blanks was then subtracted from that of the filter samples, and the result was converted to background corrected atmospheric INP number concentrations. Ultimately this procedure can be summarized as:

$N_{I N P, \text { corr }}=\left(-\ln \left(1-f_{i c e, s}\right)+\ln \left(1-f_{i c e, b}\right)\right) / V$

The corrected atmospheric INP number concentration is $N_{I N P, c o r r}$, the frozen fractions measured for the filter samples and the field blanks are $f_{i c e, s}$ and $f_{i c e, b}$, respectively, and $V$ is the volume of air sampled onto a $1 \mathrm{~mm}$ filter piece which was immersed in each examined droplet.

Uncorrected and corrected INP concentrations are shown in the two right panels of Fig. S4. $N_{I N P, \text { corr }}$ was lower than the uncorrected value by less than 2\% for two samples (June 03 and October 21) and between 5\% and 20\% for January 27 and for the samples from April 29 and May 07 below $-14^{\circ} \mathrm{C}$. Above $-14^{\circ} \mathrm{C}$, this difference was between $20 \%$ and $40 \%$ for May 07, which, compared to the range the overall signals span, is still small and within the uncertainty given in the main text. For the sample from April 29 above $-14^{\circ} \mathrm{C}$, there are clear differences between uncorrected and corrected values, going up to $80 \%$, and at the highest temperatures there were two values for which the field blank showed higher $f_{\text {ice }}$ than the sample (see red circle in lower right panel). The respective field blank had been taken on May 07, i.e., at the end of the period when the sample from April 29 was collected. Also, the sample from April 29 was amongst the lowest measured (it could not be included in the time series shown in Fig. 3 in Sec. 3.1 in the main text). Indeed, the sample of April 29 was the only one in this whole 
study for which a background signal was above the respective measurement. As it was shown above, the signal from the field blanks varied along with the signals from the sampled filters. The sample from April 29 was collected at the end of the season with low INP concentrations, and possibly the field blank taken on May 07 does not represent the background that was present during the time when the sample from April 29 was collected. Therefore, for the case of April 29, rather the attribution of this field blank to the filter, rather than the data obtained from that filter itself, might be considered problematic.

With a background as variable as that observed here, subtracting a background may induce errors. A subtraction of the background was not done in this study, for the following reasons: 1) As discussed above, even for these examples with a comparably high influence from the background, the difference between corrected and uncorrected INP concentrations was generally low. 2) A clear attribution of field blanks to related samples would, in all cases, be needed, due to the variable background, but this seems not even possible for Alert, for which the largest amount of field blanks was available. 3) The interpretation of the results from the filters presented in this study is the same for both uncorrected and background-corrected samples.

Some filters sampled during spring 2017 in Alert and from March until September 2015 in Ny Ålesund also had been examined. However, these filters had shorter sampling times of only one day and less than $60 \mathrm{~L}$ of air had been sampled onto each single circular $1 \mathrm{~mm}$ filter piece. $f_{i c e}$ determined for these filters were so close to the background determined from the blank filters, that these data were not used in this study. It should be added that for cases where a lower background can be achieved or where air with high concentrations of INP is sampled, $60 \mathrm{~L}$ of air sampled into each one of the examined droplets may suffice to get values that are well enough separated from the background. 


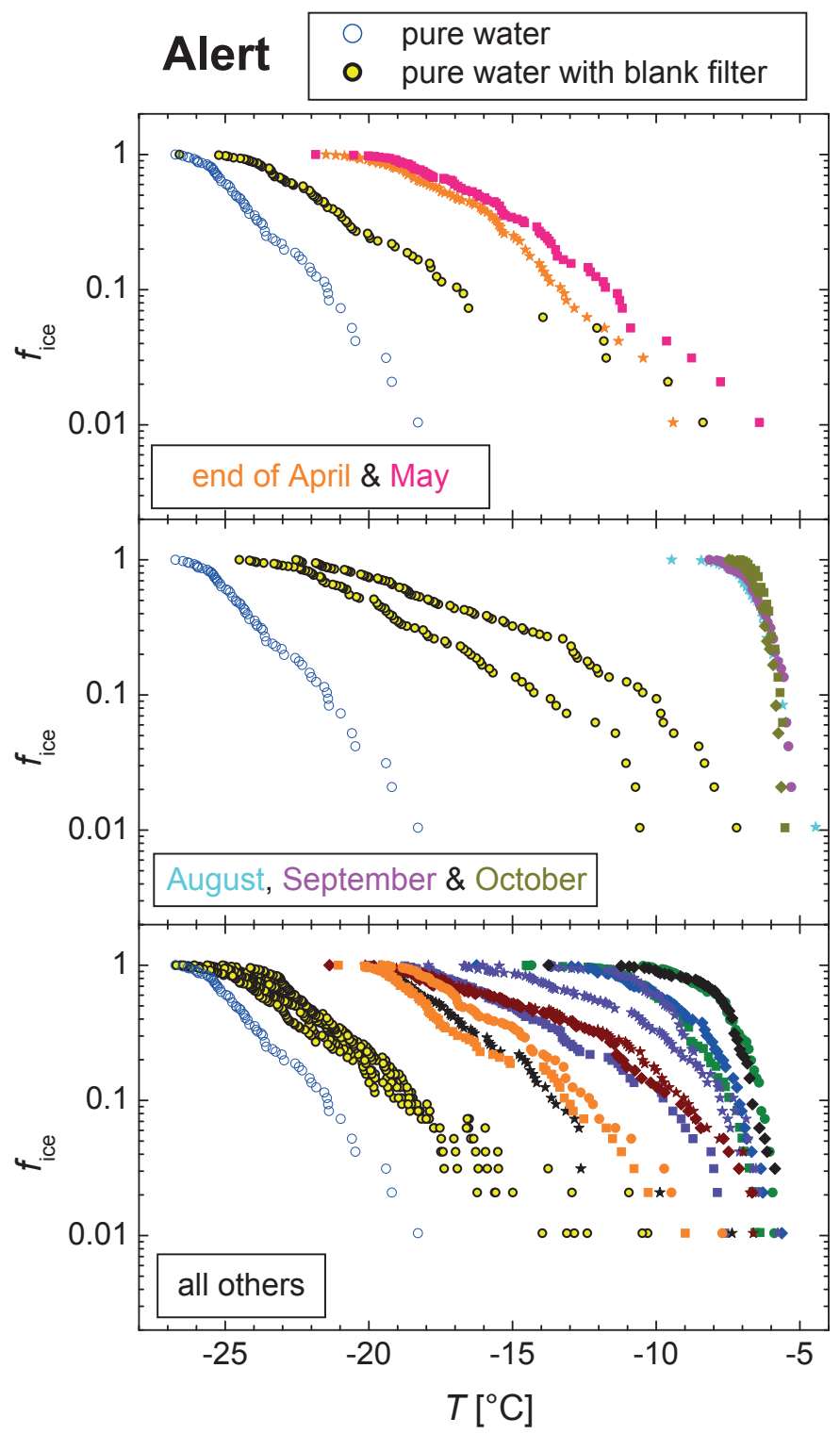

Figure S1. $f_{\text {ice }}$ derived for measurements of pure water (blue open circles), blank filters (black circles with yellow filling) and filter samples sampled prior and after the blank filter was taken. The color code for the filter samples is the same as used in Fig. 1. 


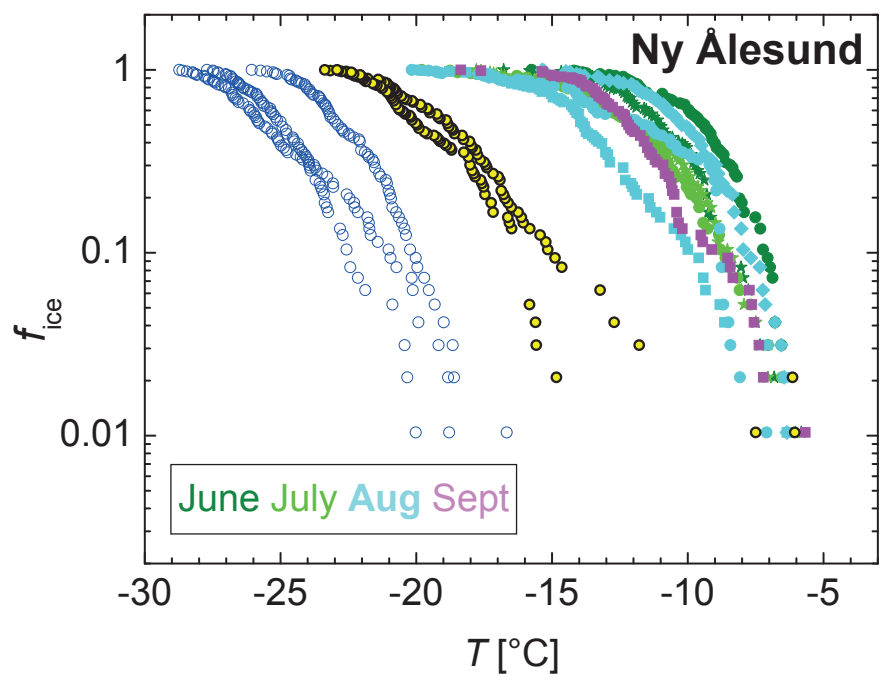

Figure S2. Similar to Fig. S1, but for Ny Ålesund.

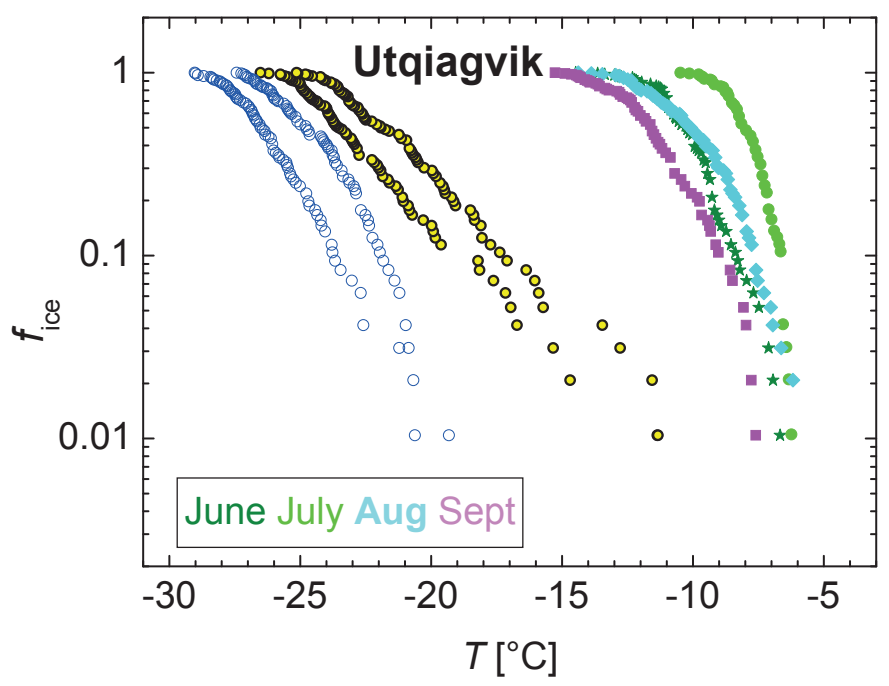

Figure S3. Similar to Fig. S1, but for Utqiagivik. 

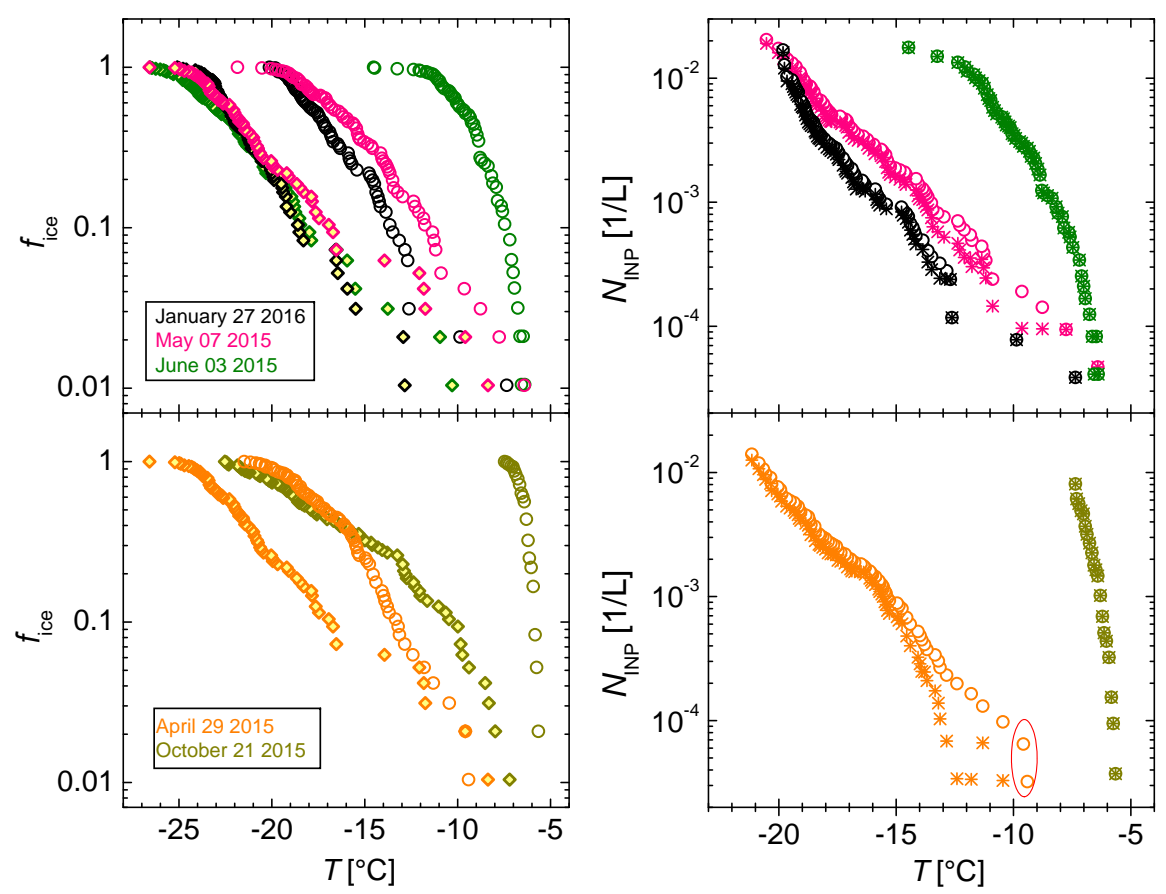

Figure S4. The two panels to the left show frozen fractions measured for five different filter samples (open circles), together with the respective field blanks (diamonds, filled in yellow). Symbol colors indicate the day when sampling of the filter sample was started. (Two separate panels were used to increase the visibility of the separate curves.) The two right panels show uncorrected and background-corrected INP concentrations (open circles and stars, respectively). The red circle in the lower right panel shows the only time observed during this study when a background signal was above the measured signal. 


\section{Back-trajectories}

Figs S6 to S8 show the back-trajectories that were derived for the 17 selected filters examined in detail in Sec. 3.3. For Utqiagivik, 5-day and 10-day back-trajectories are shown separately in Figs S7 and S8 and the information on the altitude of these back-trajectories is explicitly shown in Fig. S9.
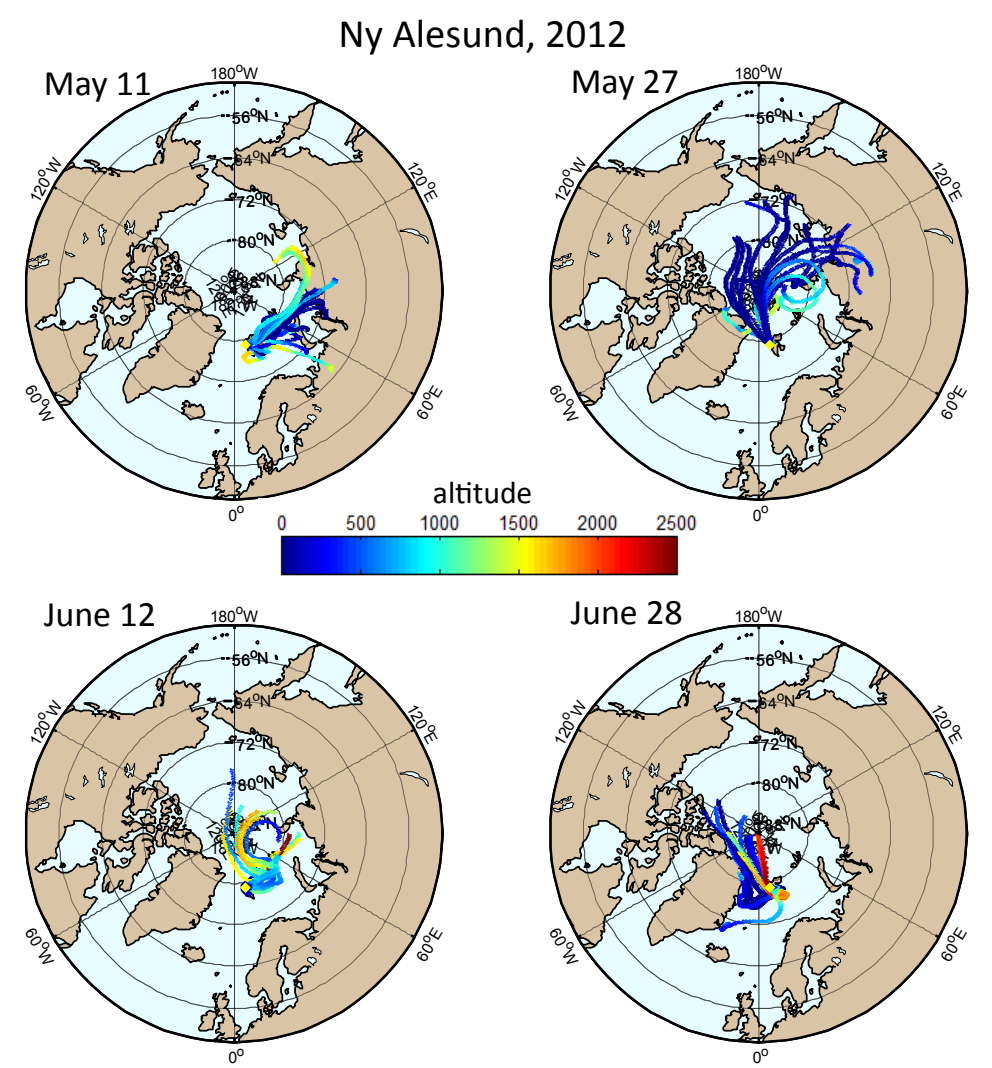

Figure S5. 5-day back-trajectories for the filter samples from Ny Ålesund discussed in Sec. 3.3. 
Alert, 2015
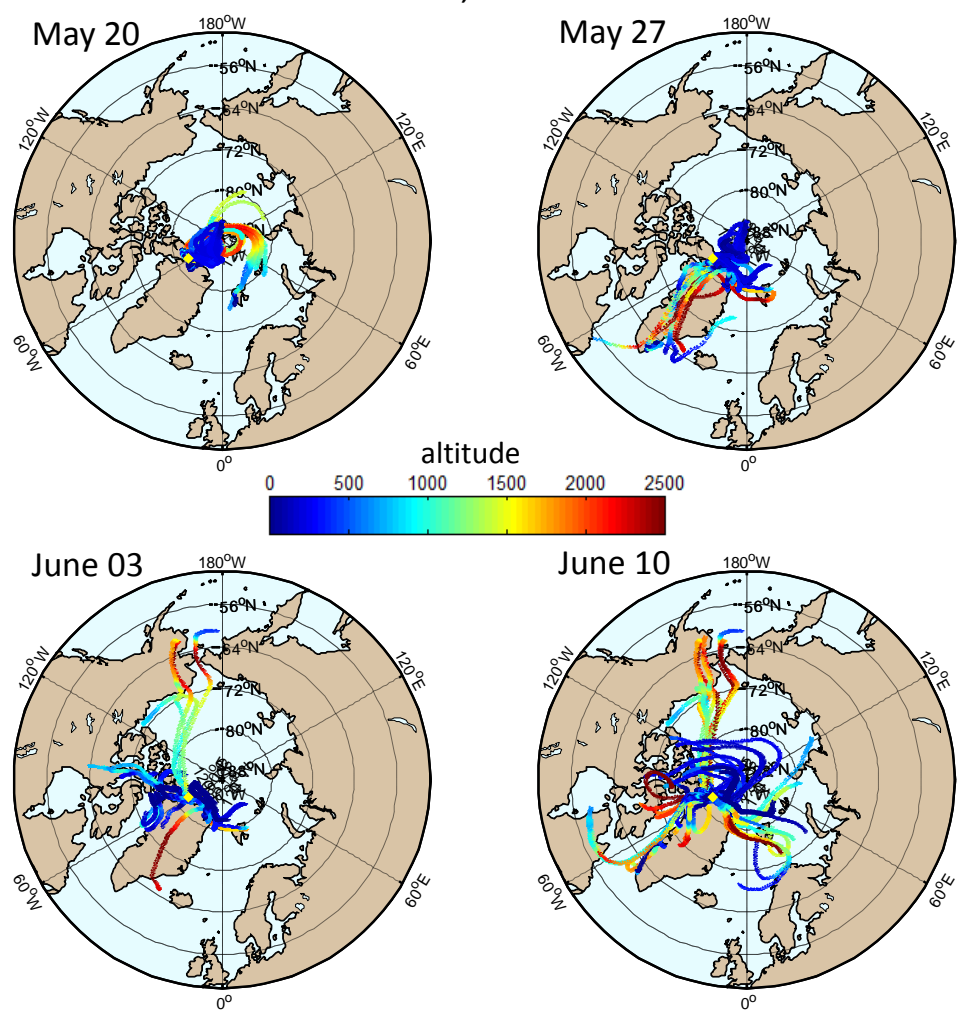

VRS, 2015
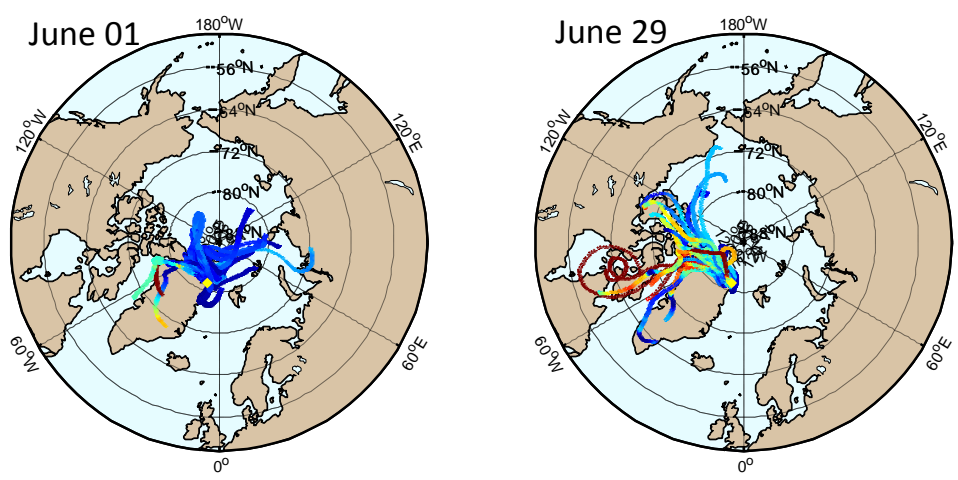

Figure S6. Similar to Fig. S5, but for Alert and VRS. 
Utqiagvik, 2013
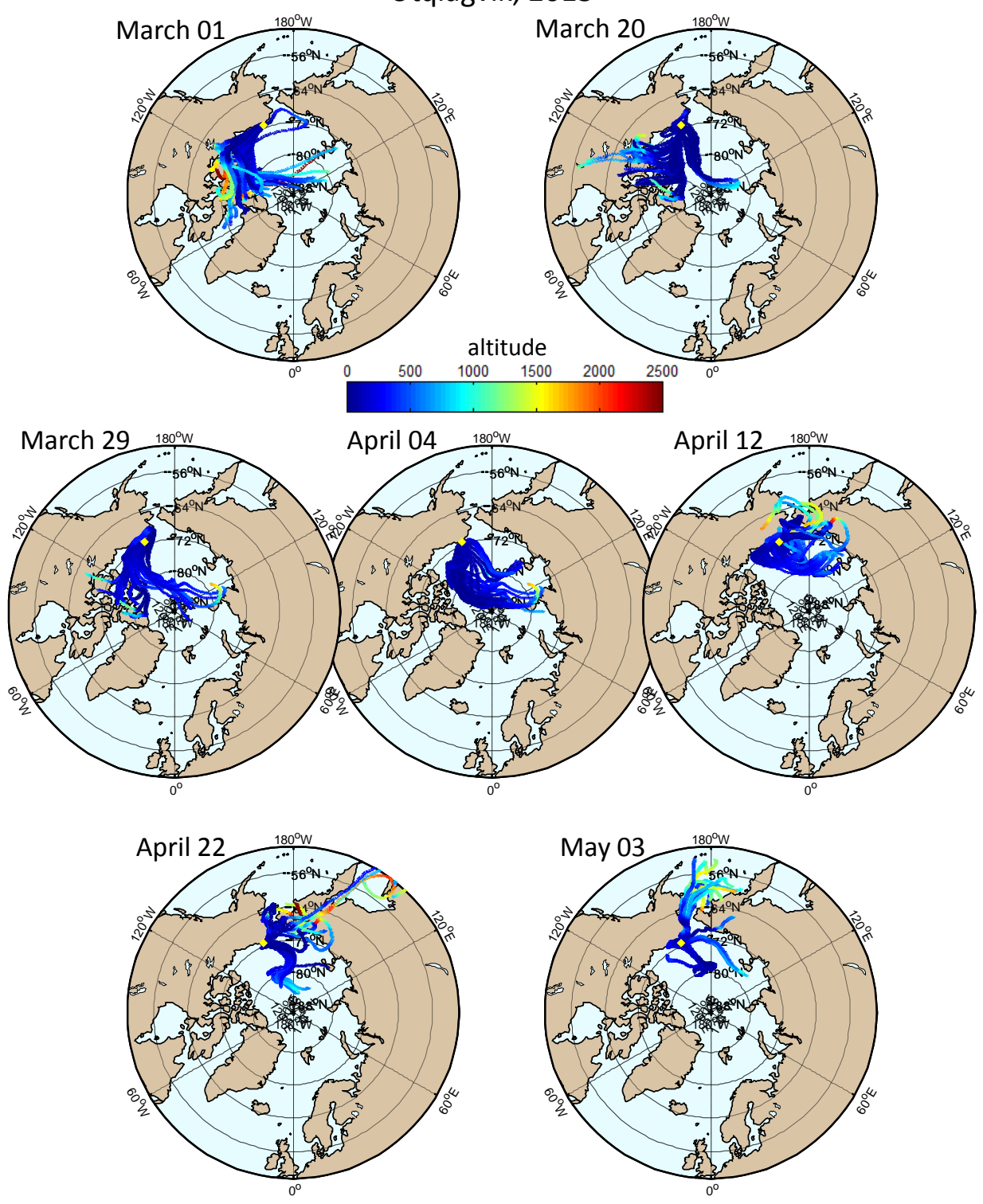

Figure S7. Similar to Fig. S6, but for Utqiagivik. 
Utquiagvik, 2013
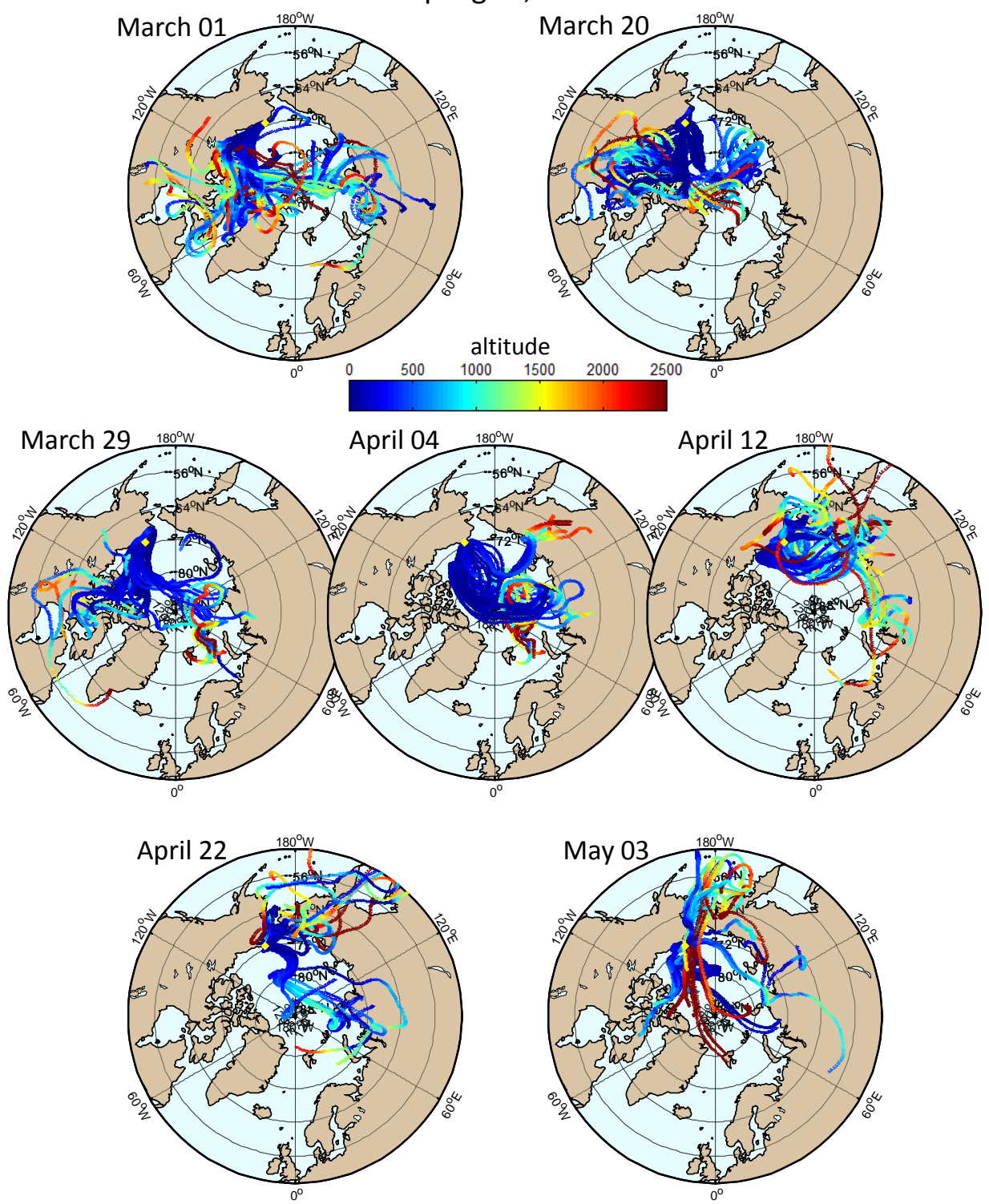

Figure S8. Similar to Fig. S7, but showing 10-day back-trajectories. 
Utquiagvik, 2013
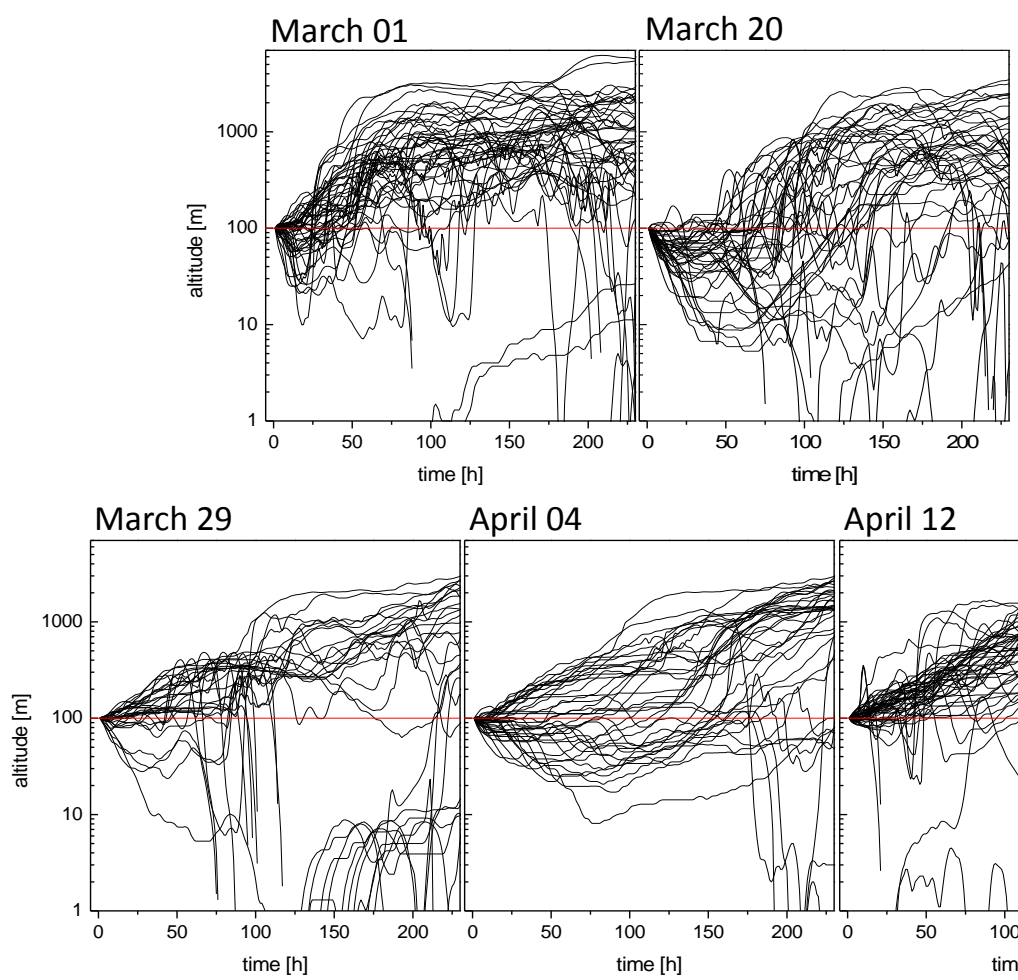

April 04

April 12

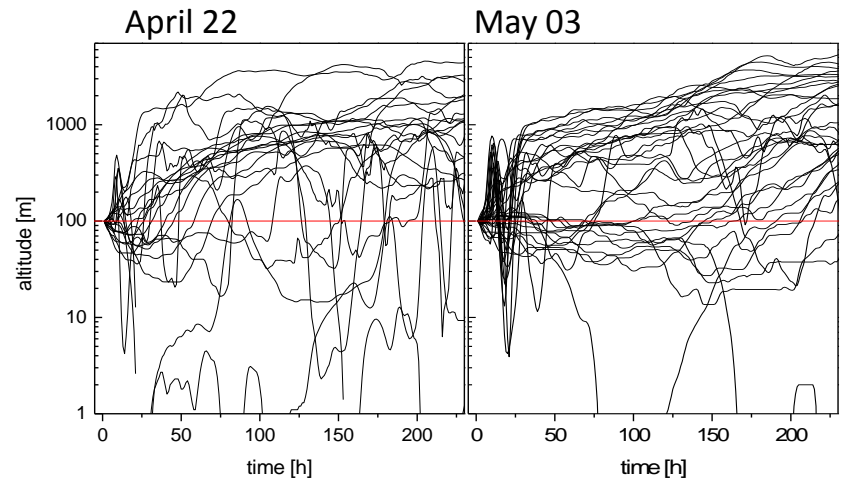

Figure S9. Altitudes of the 10-day back-trajectories displayed in Fig. S8. 


\section{Recommendations}

We felt it could help future research if we shared some recommendations, based on lessons we learned. These are the following:

- It could be advantageous to sample on filters that allow for washing off particles, as this enables to do dilution series. With this, obtained data can cover a broader $T$ range (e.g., polycarbonate membrane filters, Price et al., 2018), compared to that obtained in the present study.

- A higher time resolution used in the filter sampling will facilitate source apportionment. Still, care has to be taken to sample enough material to be above the detection limit, as for the present study samples on which less than $60 \mathrm{~L}$ of air had been sampled onto each single circular $1 \mathrm{~mm}$ filter piece (i.e., into each examined droplet) could not be used as they were too close to the background (see above, SI 1). Therefore shorter sampling times have to be counterbalanced by higher flow rates during sampling. Suppressing the filter background, if possible, would be of advantage, too. Recently, Polen et al. (2018) gave a number of recommendations related to use of and data from droplet freezing techniques as the one applied in this study, with a focus on working cleanly.

- Sampling with in-situ devices (Rogers et al., 2001; Prenni et al., 2007) can complement off-line filter analysis, measuring down to lower $T$. However, they need comparably high $N_{I N P}$ to overcome their detection limits and hence typically contribute values at lower $T$ where $N_{I N P}$ is higher. Concentration of the aerosol prior to the in-situ sampling, done e.g., in Tobo et al. (2013), can help to increase that $T$ up to which measurements can be made, increasing the range of $T$ for which overlap between in-situ and off-line techniques can be obtained.

- Parallel sampling of additional sufficient material to derive chemical composition enables more indepth testing of possible components present in INP. This might help to connect INP to their sources or to at least enable to corroborate the biogenic nature of those INP active at high $T$, using e.g., a test of the heat sensitivity of INP for the latter. It should be added that also the choice of filter material is important. Polycarbonate filters can be washed off and different analysis, including heat treatment, can be done on the suspensions. Teflon filters were found to not work well for washing off in Chen et al. (2018) and also could not be punched. When considering heat treatment, parts of sampled quartz fiber filters could be heated prior to punching filter pieces for the analysis, while suspensions can not be made as INP are retained by the fibers (Conen et al., 2012).

\section{References}

Chen, J., Wu, Z., Augustin-Bauditz, S., Grawe, S., Hartmann, M., Pei, X., Liu, Z., Ji, D., and Wex, H.: Ice nucleating particle concentrations unaffected by urban air pollution in Beijing, China, Atmos. Chem. Phys., 18, 3523-3539, https://doi.org/10.5194/acp18-3523-2018, 2018.

Conen, F., Henne, S., Morris, C. E., and Alewell, C.: Atmospheric ice nucleators active $>=-12$ degrees $\mathrm{C}$ can be quantified on PM10 filters, Atmos. Meas. Tech., 5, 321-327, https://doi.org/10.5194/amt-5-321-2012, <GotoISI>://WOS:000300876700004, 2012. 
Polen, M., Brubaker, T., Somers, J., and Sullivan, R. C.: Cleaning up our water: reducing interferences from nonhomogeneous freezing of "pure" water in droplet freezing assays of ice-nucleating particles, Atmos. Meas. Tech., 11, 5315-5334, https://doi.org/10.5194/amt-11- 5315-2018, 2018.

Prenni, A. J., Harrington, J. Y., Tjernstrom, M., DeMott, P. J., Avramov, A., Long, C. N., Kreidenweis, S. M., Olsson, P. Q., and Verlinde, J.: Can ice-nucleating aerosols affect Arctic seasonal climate?, Bull. Amer. Meteor. Soc., 88, 541-550, https://doi.org/10.1175/bams-88-4-541, 2007.

Price, H. C., Baustian, K. J., McQuaid, J. B., Blyth, A., Bower, K., Choularton, T., Cotton, R. J., Cui, Z., Field, P. R., Gallagher, M., Hawker, R., Merrington, A., Miltenberger, A., Neely III, R. R., Parker, S. T., Rosenberg, P. D., Taylor, J. W., Trembath, J., Vergara-Temprado, J., Whale, T. F., Wilson, T. W., Young, G., and Murray, B. J.: Atmospheric ice-nucleating particles in the dusty tropical Atlantic, J. Geophys. Res. Atmos., 123, https://doi.org/10.1002/2017JD027560, 2018.

Rogers, D. C., DeMott, P. J., and Kreidenweis, S. M.: Airborne measurements of tropospheric ice-nucleating aerosol particles in the Arctic spring, J. Geophys. Res., 106, 15 053-15 063, 2001.

Tobo, Y., Prenni, A. J., DeMott, P. J., Huffman, J. A., McCluskey, C. S., Tian, G. X., Pohlker, C., Poschl, U., and Kreidenweis, S. M.: Biological aerosol particles as a key determinant of ice nuclei populations in a forest ecosystem, J. Geophys. Res., 118, 10 100-10 110, https://doi.org/10.1002/jgrd.50801, <GotoISI>://WOS:000325489300003, 2013.

Vali, G.: Revisiting the differential freezing nucleus spectra derived from drop-freezing experiments: methods of calculation, applications, and confidence limits, Atmos. Meas. Tech., 19, 1219-1231, https://doi.org/10.5194/amt-12-1219-2019, 2019. 